This item was submitted to Loughborough's Research Repository by the author.

Items in Figshare are protected by copyright, with all rights reserved, unless otherwise indicated.

\title{
Experimental study on the burning rate of Methane and PRF95 dual fuels
}

PLEASE CITE THE PUBLISHED VERSION

http://dx.doi.org/10.4271/2016-01-0804

\section{PUBLISHER}

(C) SAE International

\section{VERSION}

NA (Not Applicable or Unknown)

\section{PUBLISHER STATEMENT}

This work is made available according to the conditions of the Creative Commons Attribution-NonCommercialNoDerivatives 4.0 International (CC BY-NC-ND 4.0) licence. Full details of this licence are available at: https://creativecommons.org/licenses/by-nc-nd/4.0/

\section{LICENCE}

CC BY-NC-ND 4.0

\section{REPOSITORY RECORD}

Petrakides, Sotiris, Dongzhi Gao, Rui Chen, Daniel S.A. Butcher, and Haiqiao Wei. 2016. "Experimental Study on the Burning Rate of Methane and PRF95 Dual Fuels". figshare. https://hdl.handle.net/2134/20248. 


\title{
Experimental Study on the Burning Rate of Methane and PRF95 Dual Fuels
}

\author{
Sotiris Petrakides \\ Loughborough University \\ Dongzhi Gao \\ SKLE - Tianjin University \\ Rui Chen and Daniel Butcher \\ Loughborough University \\ Haiqiao Wei \\ SKLE - Tianjin University
}

\begin{abstract}
Natural gas as an alternative fuel offers the potential of clean combustion and emits relatively low $\mathrm{CO}_{2}$ emissions. The main constitute of natural gas is methane. Historically, the slow burning speed of methane has been a major concern for automotive applications.

Literature on experimental methane-gasoline Dual Fuel (DF) studies on research engines showed that the DF strategy is improving methane combustion, leading to an enhanced initial establishment of burning speed even compared to that of gasoline. The mechanism of such an effect remains unclear.

In the present study, pure methane (representing natural gas) and PRF95 (representing gasoline) were supplied to a constant volume combustion vessel to produce a DF air mixture. Methane was added to PRF95 in three different energy ratios 25\%, 50\% and $75 \%$. Experiments have been conducted at equivalence ratios of $0.8,1,1.2$, initial pressures of 2.5, 5 and 10 bar and a temperature of $373 \mathrm{~K}$. At stoichiometric conditions, experiments in an SI engine have been also performed.

It has been found that methane and all DFs have their fastest burning rate at stoichiometric conditions whereas PRF95 at rich conditions $(\Phi=1.2)$. At lean conditions $(\Phi=0.8)$, all DFs resulted in faster combustion than PRF95, whereas methane is the slowest of all. At rich conditions, DF75 and DF50 are slower than methane. The transition mechanism between the constant volume combustion experiments and those in the engine environment resulted in a larger increase in the burning speed of methane and all DFs in comparison to that of the liquid fuel.
\end{abstract}

CITATION: Petrakides, S., Gao, D., Chen, R., Butcher, D. et al., "Experimental Study on the Burning Rate of Methane and PRF95 Dual Fuels," SAE Int. J. Engines 9(2):2016, doi:10.4271/2016-01-0804.

\section{INTRODUCTION}

There is a growing interest for energy efficient transport solutions. Environmental impact of greenhouse gas emissions, as well as future air quality, are forcing governmental bodies to continuously update their legislations, adopting challenging emission standards.

Alternative fuels have a central contribution towards compliance with future emission legislations.

Methane has been classified by a number of studies as one of the most promising alternative fuels $[\underline{1}, \underline{2}, \underline{3}, \underline{4}, \underline{5}, \underline{6}]$, mainly due to its low carbon content and its knocking resistance. However, the slow burning speed of methane has been a major concern for its use in SI engines $[\underline{7}, \underline{8}, \underline{9}]$. The slow burning speed degrades the thermal efficiency of an SI engine and it is a contributor for hydrocarbon emissions. The impact of methane hydrocarbon emissions on the greenhouse effect is higher than the impact of $\mathrm{CO}_{2}$. As emphasized in literature on experimental studies $[\underline{10} \underline{11}]$, methane-gasoline dual fuelling improves methane combustion, leading to enhanced initial establishment of burning speed even in comparison to gasoline. The mechanism behind the observed phenomena has not been perfectly understood. 
In contrast to a methane-gasoline Dual Fuel (DF) blend, substantial efforts have been made to improve the understanding of methane combustion as well as gasoline and its surrogates both in Constant Volume Combustion Vessels (CVCVs) $[\underline{12}, \underline{13}, \underline{14}, \underline{15}, \underline{16}, \underline{17}, \underline{18}, \underline{19}]$ and SI internal combustion engines $[\underline{20}, \underline{21}, \underline{22}, \underline{23}, \underline{24}]$.

Experiments in CVCVs used throughout literature to evaluate the fundamental combustion characteristics of a combustible mixture such as laminar flame speed and Markstein length. The value of Markstein length characterizes the response of the flame speed to the flame stretch. The flame stretch is induced by the curvature of the flame as well as from the nonuniformity and unsteadiness of the flow around the flame. For a positive Markstein length, the flame speed will decrease under stretching and vice versa The reported laminar flame speed of methane is lower compared to that of gasoline and its surrogates when tested at similar conditions $[\underline{15}, \underline{13}, \underline{17}, \underline{19}]$. A part of the study of Gu et al. [17] compared the laminar flame speed and Markstein length of isooctane and methane air mixtures. At 5 bar and $358 \mathrm{~K}$ the laminar flame speed of methane found to be $18 \%$ lower than that of isooctane. As emphasized [17], these two fuels responded to flame stretch differently with respect to the equivalence ratio. For methane-air mixtures, Markstein length increases with equivalence ratio whereas it decreases for isooctane-air mixtures. At lean mixtures the Markstein length of methane is lower than that of isooctane.

As far as experiments in SI engines are concerned, the findings with respect to the effects of different fuelling modes as well as operating parameters on the overall burning rate usually differ among the studies in literature. Aleiferis et al.[21] reported that at low-load conditions gasoline DI mode increase the rate of heat release as compared to PFI mode. These findings are not similar to those of Zhu et al [22]. Aleiferis et al [23] emphasizing the difficulties in drawing general conclusions from comparisons of experimental data conducted in different internal combustion engines in literature, suggesting that changes in hardware and operating strategies can substantially change the outcomes of a test.

\section{BURNING RATE DEFINITIONS}

The mass burning rate in a homogeneous SI engine can be defined as,

$$
\dot{m}_{b, \text { engine }}=\rho_{u} A_{f} S_{l} I_{0}
$$

where $\rho_{u}$ is the unburned gas density, $A_{f}$ is the actual flame surface area, $S_{l}$ is the laminar flame speed, and $I_{0}$ is the flame stretch factor.

It can be derived [as shown in Appendix A1] that the mass burning rate is depended on the in-cylinder pressure, $I$, unburned gas temperature, $T_{u}$, equivalence ratio, $\Phi$, composition, $c_{i}$, and turbulence characteristics, $u_{t}$, as shown in equation 2 . The dependence of burning rate on the mentioned parameters is highly nonlinear.

$$
\dot{m}_{b, \text { engine }}=f\left(P, T_{u}, \Phi, c_{i}, u_{t}\right)
$$

The parameters that affect the burning rate (eq. 2) are also dependent variables. For example, a change in composition will affect the unburned gas temperature. To help the reader appreciate the mentioned phenomena, a simplified engine compression stroke is modeled with an adiabatic variable volume model, and a compression ratio of 10:1. Three different fuels have been considered at stoichiometric conditions. The fuels consist of $\mathrm{CH}_{4}$, a binary blend of primary reference fuels commonly known as PRF95 (95\%volliq of iso-octane and 5\%volliq n-heptane), and a DF blend (DF50) with half of its energy contributing from $\mathrm{CH}_{4}$ and half from PRF95.

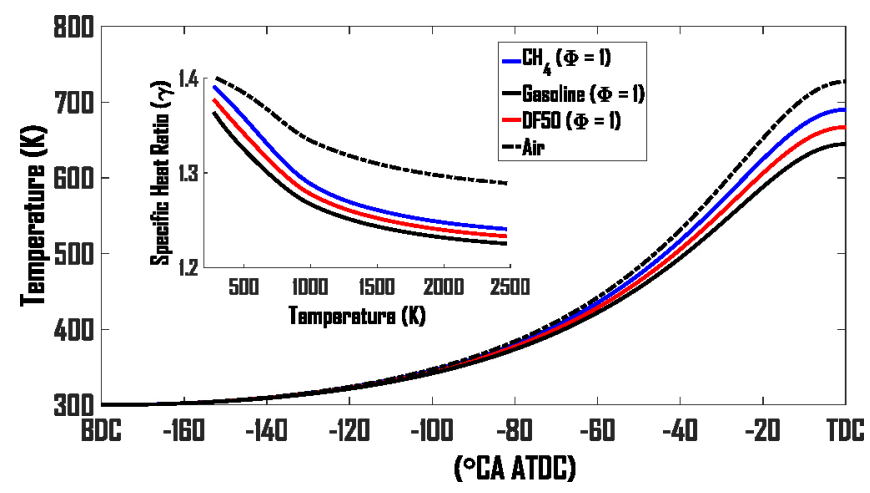

Figure 1. Effect of piston compression on the unburned gas temperature during different fuelling modes

As can be observed from Figure 1 at identical initial conditions and for the same compression, a change in fuelling mode will lead to different compressive temperatures attributed to the different specific heat ratios among fuels. For completeness, the compressive temperature of pure air is also shown in Figure 1. Such analysis illustrates the difficulties in drawing general conclusions from engine experimental data with regards to the burning characteristics of different fuels. That highlights the need for experiments under the same initial conditions in order to draw more confident conclusions when comparing the effects of a variety of fuels.

Experiments in CVCVs allow for the same initial conditions among the different tested fuels due to the nonexistence of piston compression and the minimization of turbulent flow structures. The flow structures inside the vessel can be minimized by giving time for quiescence after the filling process has been completed. Therefore the effect of turbulence on the burning rate can be reasonably neglected. Moreover, the time of quiescence enhances the mixing of air and fuel, limiting any spatial differences of the air to fuel ratio inside the vessel as can be the case in SI engines. Flame instabilities manifested as cellular structures on the flame surface can lead to a selfturbulirizing effect inside the CVCV [17]. The phenomenon of self-turbulirizing will enhance the burning rate due to an increase of the flame's surface area. Flame instabilities can also occur in an engine environment. However in an engine, the stronger effects of turbulence on the burning rate are masking the ones of instability.

The mass burning rate inside the CVCV can be defined as,

$$
\dot{m}_{b, C V C V}=\rho_{u} A_{f}^{\prime} S_{L} I_{0}^{\prime}
$$


It can be derived [Appendix A2] that the mass burning rate is dependent on the pressure, unburned gas temperature, equivalence ratio and composition.

$$
\dot{m}_{b, C V C V}=f\left(P, T_{u}, \Phi, c_{i}\right)
$$

At the time of ignition, three out of four parameters that affect the burning rate inside the CVCV as shown in equation 4 can be constrained, and the effects of the fourth parameter on the overall burning rate can be evaluated with confidence.

For a homogeneous mixture of the same equivalence ratio and composition, the transition mechanism characterizing the difference in burning rate from the constant volume combustion experiments to those in the engine environment can be revealed by considering the equations 2 and 4 . For a particular fuelling mode, the contributors of the transition mechanism as indicated in equation 5 are the effects of turbulence on the burning rate as well as the difference in temperature and pressure due to piston compression.

$$
\begin{gathered}
\dot{m}_{b, C V C V}-\dot{m}_{b, \text { engine }}=f\left[\left(P_{C V C V}-P_{\text {engine }}\right),\left(T_{C V C V}-\right.\right. \\
\left.\left.T_{\text {engine }}\right), u_{t}\right]
\end{gathered}
$$

Where $P_{C V C V}, T_{C V C V}$ is the pressure and temperature inside the $\mathrm{CVCV}$ and $P_{\text {engine }}, T_{\text {engine }}$ is the pressure and temperature in the engine environment.

Following the previous discussion, it is evident that for a confident comparison of the burning characteristics of different fuels, there is a clear need for combustion experiments under the same initial conditions. In contrast to methane as well as gasoline and its surrogates, the burning rate of methane-gasoline dual fuel blends has not been adequately investigated. It is therefore the aim of this study, to experimentally investigate how a change in DF ratio is affecting the burning rate under the same initial conditions. In the current experimental work PRF95 has been used as the liquid fuel. Methane has been used as the gaseous fuel. The duration of $10 \%$ and $10-90 \%$ Mass Fraction Burned (MFB) are measured in a CVCV at initial pressures of 2.5, 5, $10 \mathrm{bar}$ (abs), equivalence ratios of $0.8,1,1.2$, and a temperature of $373 \mathrm{~K}$. The particular pressure conditions have been selected to reflect idling, part and full load conditions in a heavily turbocharged engine at the point of spark. The particular temperature has been selected to allow reference with the available combustion characteristics of methane and PRF95 that have been already published in literature. The same MFB durations have been measured in an SI engine at stoichiometric conditions. The transition mechanism characterizing the difference in the response of MFB with DF ratio between constant volume combustion experiments and those in the engine environment is also investigated.

\section{METHODOLOGY}

\section{Constant Volume Combustion Vessel}

A $100 \mathrm{~mm}$ inner diameter cylindrical combustion vessel with a volume of $2.2 \mathrm{~L}$ was employed for the experimental CVCV study. The experimental setup is illustrated in Figure 2. The entire vessel was uniformly preheated by a set of electrical heating elements totaling $3.2 \mathrm{~kW}$. One of the heaters was fully inserted inside the vessel to induce a transient temperature difference only during the filling process. The temperature difference evoked natural convection to stir the mixture enhancing the mixing of fuel and air. Similar technique has been used in [13]. The interior air temperature was controlled within $3 \mathrm{~K}$ using a closed-loop feedback controller set to $373 \mathrm{~K}$. The temperature could also be observed manually from a second temperature sensor mounted on the top of the vessel. The pressure rise during the combustion process was recorded using a Kistler 6113B pressure transducer at $6 \mathrm{kHz}$. The mixture was ignited using a slightly modified standard ignition plug with extended electrodes. The ignition system generated a spark with duration of 0.7 $\mathrm{ms}$ and the timing was synchronized with the interior pressure rise recording. For safety reasons, a $6 \mathrm{MPa}$ pressure release valve was installed on the combustion vessel.

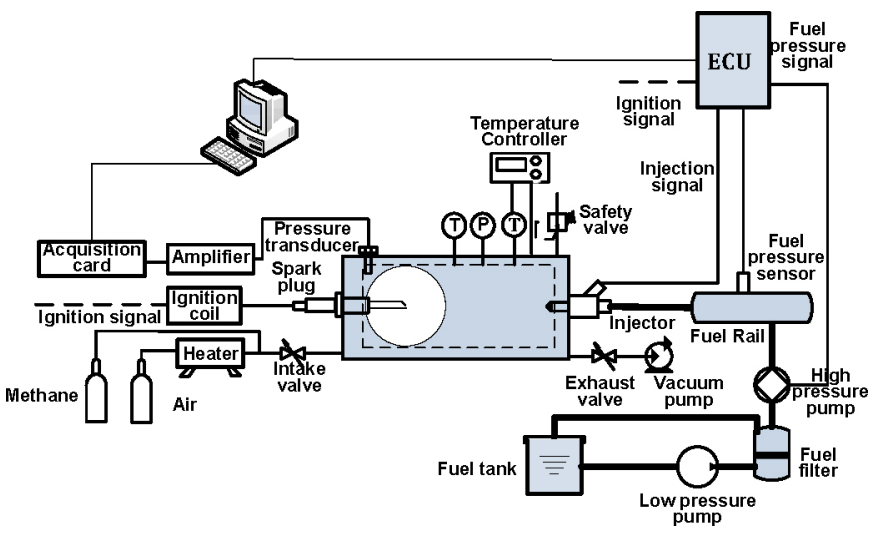

Figure 2. Schematic diagram of the CVCV setup

\section{Dual Fuel Mixture Preparation}

The dual fuel blends consist of Methane and PRF95 in three different energy ratios $(25,50,75)$, that have been defined based on equation 6. A blend with $25 \%$ of its energy contributing from methane was labelled as DF25, with 50\% DF50, and for $75 \%$ DF75.

$$
D F_{\text {Ratio }}=\frac{M_{C_{4}} \times L H V_{C H_{4}}}{M_{P R F 95} \times L H V_{P R F 95}+M_{C H_{4}} \times L H V_{C H_{4}}}
$$

Three different equivalence ratios have been tested $(0.8,1,1.2)$. The different equivalence ratios have been calculated using the method of chemical balance and assuming products of complete combustion. High purity technical air was used with an oxidizer concentration $\left[\mathrm{O}_{2} /\left(\mathrm{O}_{2}+\mathrm{N}_{2}\right)\right]$ of $0.2 \pm 0.01$.

In every experimental condition, the equivalence ratio was prepared inside the vessel using the partial pressure method. Initially the vessel was heated up to the desired temperature $(373 \mathrm{~K})$. The necessary 
amount of liquid and gaseous fuel was determined depending on the targeted dual fuel ratio, equivalence ratio, and the associate pressure. The liquid fuel was injected into the combustion vessel using a multi-hole gasoline direct injector with an injection pressure of 12 $\mathrm{MPa}$. The injected fuel mass was controlled by individual injections using pre-calibrated data. The pre-calibration process involves the determination of the mass of liquid per single injection. After the injections were completed, two minutes was given to allow for complete evaporation of the liquid fuel. Considering the correct increase of pressure change caused by the evaporation of the liquid fuel compared to the thermodynamic ideal-gas law calculations, methane and then air was fed in slowly using a fine needle valve and a pressure transducer to control the filling process. The technical air was heated by an external heater before flowing into the combustion vessel to better approximate an isothermal filling process. After the filling process was completed, the heater mounted inside the vessel was turned off, and 3 minutes of quiescence has been given to minimize any flow structures and/or temperature stratifications inside the vessel. The quiescence time also enhance the homogeneous mixing of fuel an air.

For each tested condition, the described experimental procedure that allowed the evaluation of the Heat Release Rate (HRR) and therefore the duration of $10 \%$ and $10-90 \%$ MFB was carried out at a minimum of three times. The average values of MFBs are reported as well as error bars evaluated based on standard error.

\section{SI Internal Combustion Engine}

A $0.5 \mathrm{~L}$ displacement, single cylinder SI research engine shown at Figure 3 with a bore of $88 \mathrm{~mm}$, stroke of $82.1 \mathrm{~mm}$ and compression ratio of 10:1 was used for the SI engine experiments. The engine speed and load were held constant at 2000 RPM and 2.7 bar IMEP respectively. As suggested by Stanfield [25] and supported by the authors, this has been a common industry test condition and typical of the NEDC test. In the current engine, Stanfield [25] has quantified the bulk incylinder air motion reporting values of the tumble and swirl ratio at the same test condition.

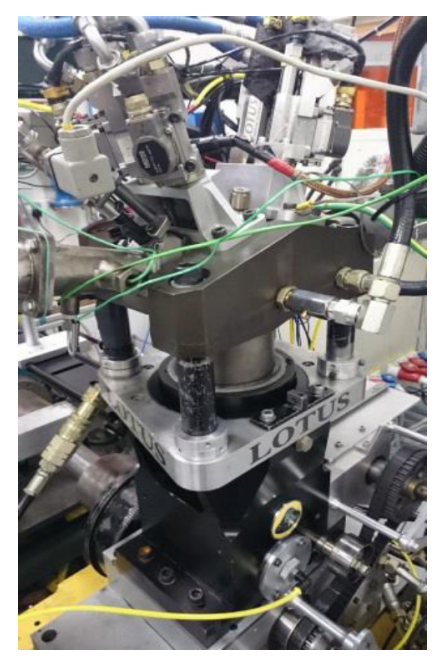

Figure 3. Single cylinder research engine
To allow for the gaseous experiments, the engine was fitted with a natural gas port fuel injector, Bosch NGI-2. The injector was supplied with compressed natural gas ( $92-96 \% \mathrm{CH}_{4}$ mass content) via a two-stage regulator which allowed regulation up to $13 \mathrm{bar}$; this was set to 4 bar for all tested conditions. Fuel injection pressure was chosen to be within the linear operating range of the injector specification where existing characterization data was available. The engine specifications and operating conditions are presented in Table 1.

Table 1. Engine specifications and operating conditions

\begin{tabular}{|l|l|}
\hline Displaced Volume & $0.5 \mathrm{~L}$ \\
\hline Bore & $88 \mathrm{~mm}$ \\
\hline Stroke & $82.1 \mathrm{~mm}$ \\
\hline Compression Ratio & $10: 1$ \\
\hline Intake Valves Open / Close / Lift & $15^{\circ} \mathrm{BTDC} / 45^{\circ} \mathrm{ABDC} / 9.35 \mathrm{~mm}$ \\
\hline Exhaust Valves Open / Close / Lift & $45^{\circ} \mathrm{BTDC} / 15^{\circ} \mathrm{ABDC} / 9.35 \mathrm{~mm}$ \\
\hline Engine Speed & $2000 \mathrm{RPM}$ \\
\hline Engine Load & $2.7 \mathrm{bar}$ IMEP \\
\hline Spark Timing & $35^{\circ} \mathrm{BTDC}$ \\
\hline
\end{tabular}

For all experiments, gas was injected into the manifold immediately after the intake valves are closed to maximize the available time for mixing. Gasoline fuel was introduced via an early direct injection $\left(30^{\circ}\right.$ ATDC) using a multi-hole GDI injector and an injection pressure of $12 \mathrm{MPa}$. This timing was chosen to maximize the time for mixing whilst not impinging the piston. For all experiments, spark timing was set constant at $35^{\circ} \mathrm{BTDC}$ and the equivalence ratio to stoichiometric. Control of the fuelling as well as the ignition was provided by an AVL 2410 instrument controller. This allowed full flexibility of the start and duration of each injector independently.

To calculate the required fuelling durations, the natural gas run was carried out first. Throttle position and injection duration was adjusted in order to achieve the target engine load of 2.7 bar IMEP. The mass of gas required at this condition is calculated from a previously obtained injector calibration relationship. For subsequent runs with dual fuel, this mass is divided according to the required dual fuel ratio, to give the desired natural gas mass. The gasoline injection duration is then adjusted in parallel with a fine tune of the throttle position, until the same engine load of 2.7 bar IMEP is achieved at stoichiometric operation. For example, at DF50, half of this amount of natural gas is injected ensuring that approximately $50 \%$ of the required energy to achieve the engine load comes from the natural gas, with the other $50 \%$ from the adjusted gasoline injection.

The process for each test condition required the engine head to first be heated using the lubricating oil to a temperature of 318-323 K. The engine was then motored at 2000 RPM before activating the ignition 
coil and injectors. The engine is allowed to reach a predetermined liner exterior temperature to ensure consistency between the readings before data acquisition is started.

Two data acquisition systems were utilized for the work. The first was used to monitor temperatures at a low sample rate $(1 \mathrm{~Hz})$ via K-type thermocouples. Ambient, cylinder head, cylinder liner, air intake and exhaust temperatures were closely monitored throughout the experiments. AFR was monitored at low speed via an ECM AFRecorder 1200 which uses a lambda probe in the exhaust and allows for a custom $\mathrm{H} / \mathrm{C}$ ratio to be set; this is vital whilst considering various fuels.

High speed (crank angle resolved) acquisition was achieved using an AVL Indiset Advanced system which allowed real-time display of cylinder pressure as well as calculated performance parameters such as IMEP and COV. For each tested condition, 250 engine cycles were recorded for analysis with this system to allow for an average cycle to be calculated and analyzed. Pressures in the intake and exhaust manifolds as well as gas fuel pressure and in cylinder pressure were obtained; the latter using a water-cooled Kistler 6043A60 transducer fitted in the cylinder head.

\section{Heat Release Analysis}

Whilst much of the data is recorded using the acquisition system described, post-test analysis was carried out using an in-house MATLAB code. The purpose of the in-house code is to allow consistent analysis of the experimental data acquired in the engine as well as in the CVCV environment.

The rate of heat release in an SI engine can be obtained by considering the instantaneous pressure and volume within the cylinder as well as the value of the specific heat ratio of the combustible mixture [26]. For a comparison within the same engine and similar operating conditions, models representing heat transfer and blow-by are often omitted leading to the equation 7 .

$$
d Q_{c h}=\frac{\gamma}{\gamma-1} P d V+\frac{1}{\gamma-1} V d P
$$

Pressure (P) and Volume (V) are recorded at each crank angle, however the specific heat ratio $(\gamma)$ must be calculated as it is a function of temperature pressure and composition. The mass of trapped air is evaluated from the MAF meter, during the time the intake valves are open.

From the time of valve closing, the average charge temperature at each crank angle can be calculated by considering an ideal gas with mass according to the total trapped mass (fuel + air) and a pressure and volume as recorded. A chemical kinetics solver, Cantera is used within the MATLAB code to calculate the specific heat ratio at each crank angle from a given pressure, temperature and fuel/air composition. Equation 7 is then evaluated at each crank angle to give the HRR. The HRR is then integrated from time of spark and normalized to allow MFB rates to be evaluated.
Similar methodology applies for the calculation of MFB rates inside the CVCV. Obviously the rate of change of volume $(\mathrm{dV})$ is zero during a constant volume combustion experiment, leading to the equation 8 .

$$
d Q_{c h}=\frac{1}{\gamma-1} V d P
$$

Prior to combustion, the pressure as well as temperature is constant in the CVCV. Knowing the composition of the combustible mixture, and using ideal gas law, the trapped mass of fuel and air can be obtained. Equation 8 is then evaluated at each sampling point to give the HRR. The HRR is then integrated from time of spark and normalized to allow MFB rates to be evaluated.

\section{RESULTS - DISCUSSION}

\section{Burning Rate in CVCV}

The mean pressure traces and associated curves of MFB are shown for all fuels in Figure 4 and $\underline{5}$, for a stoichiometric equivalence ratio and an initial pressure of 5 Bar.

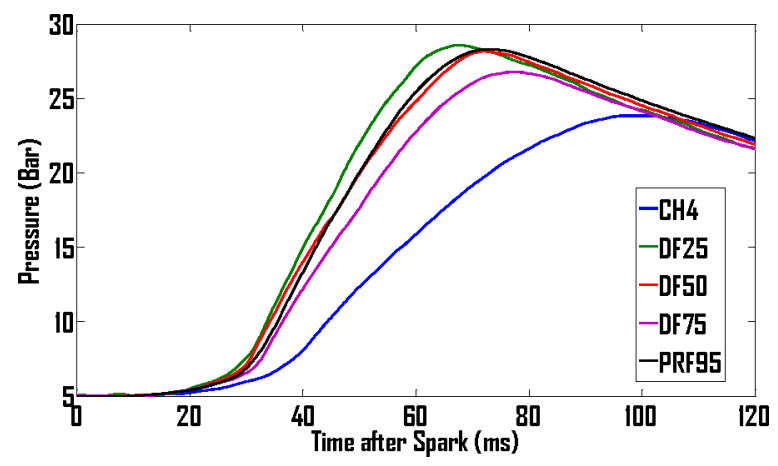

Figure 4. Recorded pressure traces in $\mathrm{CVCV}$ at $\Phi=1, \mathrm{P}_{\text {initial }}=5$ bar

The highest peak pressure was achieved by DF25 and the lowest by $\mathrm{CH}_{4}$. The DF50 and PRF95 have similar peak pressures followed by DF75. The pressure of DF50 is initially higher than PRF95. However as the combustion proceeds the pressure trace of PRF95 cross the one of DF50.

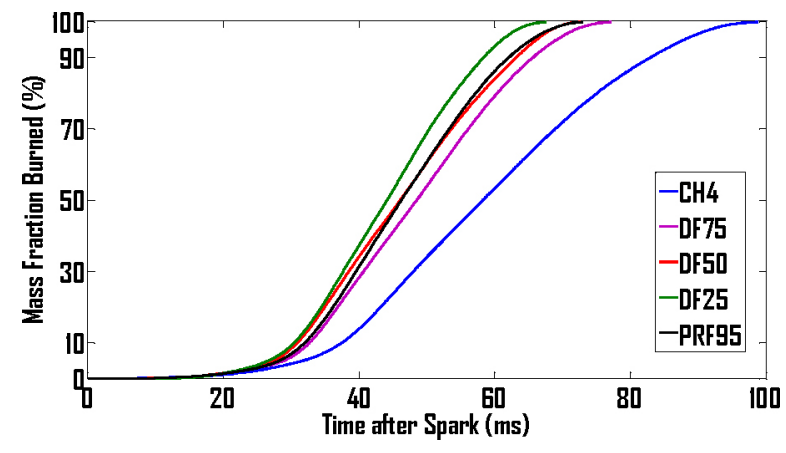

Figure 5. Calculated MFB rates at $\Phi=1, \mathrm{P}_{\text {initial }}=5$ bar 
The phasing of the various percentages of MFB illustrates similar trends with the mean pressure traces. For an efficient presentation of the extensive experimental results, only the duration of $0-10 \%$ MFB and $10-90 \%$ MFB is illustrated for the rest of the tested conditions.

In the current study, the duration of $0-10 \%$ MFB has been used as an indication of the overall burning rate during the initial flame development regime for both engine and CVCV experiments. Similarly, the duration of $10-90 \%$ MFB is indicative of the overall burning rate during the developed flame regime for both experimental environments. At a pressure of 5 bar, the MFB durations for the development and the developed flame regime are shown in Figure 6 for the five tested fuels.

At lean conditions $(\Phi=0.8)$, all DFs resulted in a faster burning rate (lower MFBs) as compared to PRF95 and to a higher extent methane in both regimes. In the developing flame regime the average burning rate of all DFs is $22 \%$ and $37 \%$ higher compared to PRF95 and methane respectively. Among DFs, DF50 was found to be the fastest and DF25 the slowest. In the developed flame regime, the average burning rate of all DFs in comparison to PRF95 as well as methane is higher by $27 \%$ and $53 \%$ respectively. Among DFs, DF75 was found to be the slowest and DF50 the fastest.
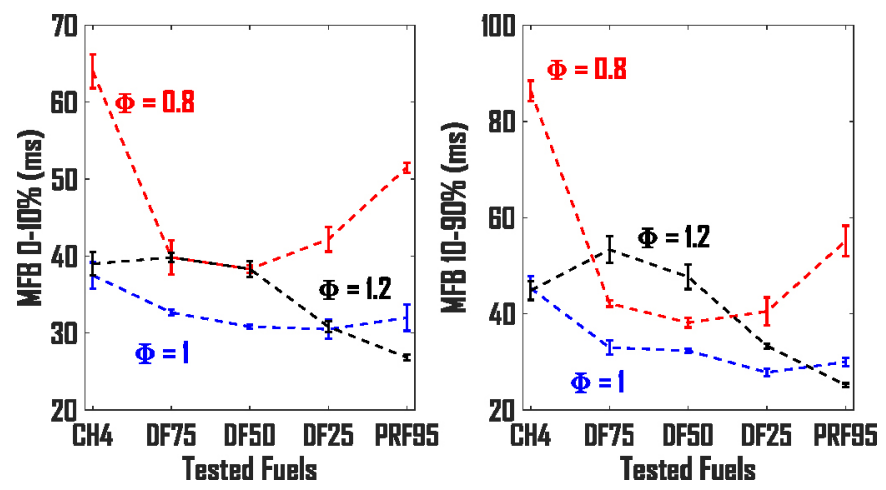

Figure 6. MFB rates for all tested conditions at $\mathrm{P}_{\text {initial }}=5$ bar

At stoichiometric conditions $(\Phi=1)$, DF50 and DF25 are 5\% faster than PRF95 in the development flame regime. DF75 is marginally slower than PRF95 and methane is the slowest of all. During the developed flame regime all DFs have faster burning rates in comparison to methane but only DF25 is 7\% faster than PRF95.

At rich conditions $(\Phi=1.2)$, the difference in burning rate for DF75, DF50 and CH4 is within 4\% in the developing flame regime. DF25 is faster than $\mathrm{CH}_{4}$ and slower than PRF95. In the developed flame regime, the burning rate of DF75 and DF50 is even slower than that of methane whereas PRF95 showed the fastest burning rate.

As far as PRF95 is concerned, as reported in literature [13] at similar initial conditions $(5 \mathrm{Bar}-373 \mathrm{~K})$, the value of $\mathrm{S}_{\mathrm{L}}$ is $10 \%$ higher at $\Phi=$ 1 as compared to $\Phi=1.2$ (the fundamental combustion characteristics of PRF95 has been assumed similar to those of iso-octane). This is not reflected in the MFB durations measured in the current study. In contrast, the duration of MFB $0-10 \%$ is $16 \%$ higher at $\Phi=1$ in comparison to $\Phi=1.2$ for a PRF95-air mixture. Moreover, at $\Phi=0.8$ the value of $S_{1}$ is $21 \%$ lower compared to that at $\Phi=1.2$, whereas the difference in MFB $0-10 \%$ is $48 \%$ [13]. Similar trends can be observed in the developed flame regime. It is clear that the mechanism behind the phenomena cannot be solely explained by the laminar flame speed. During the initial stages of combustion, due to the inverse proportionality of the flame stretch rate to the flame radius [Appendix A1], the flame will experience the highest levels of stretching. As the flame develops and the flame radius is increasing, the stretch rate is reduced. Therefore, it is expected that the value of Markstein Length will have a dominant influence on the burning rate during the initial stages of combustion for all fuels. It has to be noted that phenomena of flame instability is also affecting the burning rate.

As far as methane is concerned, during the developing flame regime the burning rate at stoichiometric conditions is $4 \%$ and $41 \%$ faster than in rich and lean conditions respectively. During the developed flame regime stoichiometric and rich equivalence ratios resulted to give the same overall burning rates.

During the developing flame regime, the burning rate of both DF75 and DF50 is similar under lean and rich conditions. In the developed flame regime, the overall burning rate of both DF75 and DF50 is on average $20 \%$ faster under lean conditions as compared to the rich operation whereas its $19 \%$ slower as compared to the stoichiometric conditions.

At stoichiometric and rich conditions, DF25 resulted in the same burning rates in the developing flame regime. Under lean conditions, the burning rate is $27 \%$ slower compared to the stoichiometric and rich conditions. In the developed flame regime, DF25 showed the fastest burning rate at stoichiometry, and the slowest at lean conditions.

Summarizing the effects of the various fuels and different AFRs on the burning rate, it has been found that the slowest burning rate corresponds to methane at lean conditions whereas the fastest to PRF95 at rich conditions. All DFs give their fastest burning rate at stoichiometric conditions. Interestingly, at lean conditions all DFs are faster than PRF95 and to larger extent methane in both regimes. At rich conditions, PRF95 is the fastest of all whereas DF75 and DF50 are even slower than methane.

Having evaluated the dependence of fuel and AFRs on the burning rate, the effects of different initial pressure can now be evaluated. At stoichiometric conditions, the burning rates in both the developing and developed flame regime are illustrated in Figure 7 for the three tested pressures.
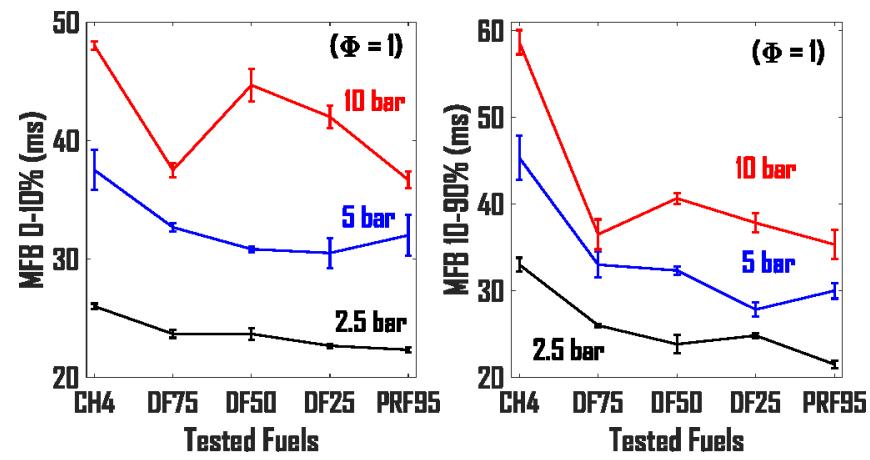

Figure 7. Effects of Pressure on the MFB rates at $\Phi=1$ 
It can be observed that in both flame regimes the duration of MFB is increased with pressure for all fuels. As reported in literature, the laminar flame speed of methane and PRF95 (assumed to have the same combustion characteristics to isooctane) is decreased linearly with pressure [17]. Therefore the burning rate will also be decreased. When the initial pressure is increased from 2.5 to 10 bar, the burning rate during the developing flame regime is decreased by $46 \%$ for methane as well as for DF50 and 40\% for PRF95. In the developed flame regime, the percentage decrease in burning rate is similar as in the developing regime.

In both flame regimes, the burning rate of all tested fuels at 2.5 bar follows a similar trend to the already discussed trend at 5 bar. On the other hand, when the initial pressure is increased to 10 bar, the response of the burning rate is substantially different from the two lower pressures. The unusually fast burning rate of DF75 at 10 bar is likely to be due to an unstable flame. The propensity of a flame to instability is increased with pressure especially for combustible mixtures of low Markstein lengths. For lean to stoichiometric AFRs, the Markstein length of methane is lower than PRF95 whereas at rich conditions is higher than PRF95 [17].

At lean conditions, the burning rates corresponding to the three different initial pressures are depicted in Figure 8. It has to be noted that due to the unnoticed inaction of the acquisition system only two repeats have been captured for the DF25 and PRF95 fuels at lean conditions $(\Phi=0,8)$ and a pressure of 10 bar. Although error bars could not be calculated for these two fuelling modes, the maximum percentage difference between their two repeats for MFB 0-10\% and MFB $10-90 \%$ was less than 2\%. Similarly to the stoichiometric conditions, in both flame regimes the burning rate of all tested fuels at 2.5 bar follows a similar trend with that at 5 bar. The negative effect of pressure on the burning rate is also evident at lean conditions. The only exception corresponds to methane at an increase in pressure from 5 to $10 \mathrm{Bar}$. At a pressure of 10 bar the flame is likely to become unstable resulting in an increase in burning rate that will mask the effects of pressure. When the initial pressure is increased from 2.5 to 10 bar the percentage decrease in burning rate is higher than that at stoichiometric conditions, implying a stronger effect of pressure on the burning rate.
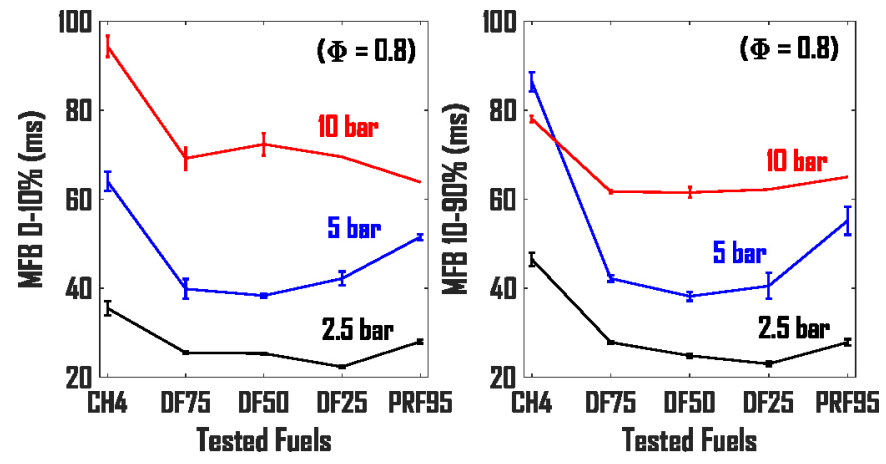

Figure 8. Effects of Pressure on the MFB rates at $\Phi=0.8$

The burning rates at rich conditions are illustrated in Figure 9 for the three tested pressures. Similarly to lean and stoichiometric conditions, in both flame regimes the burning rate of all tested fuels at 2.5 bar is following a similar trend with that at 5 bar. As can be observed from Figure 9 in the developing flame regime, methane as well as all DFs have a faster burning rate at 10 bar as compared to 5 bar. For DF75 and DF50 the burning rate at 10 bar is even faster than at 2.5 bar. It seems that all fuels have an unstable flame at a pressure of 10 bar. During the developed flame regime all DFs showed their fastest burning rate at a pressure of 10 bar. For PRF95 the fastest burning rate corresponds to 2.5 bar and the slowest to 10 bar in both flame regimes. This may be due to the fact that at rich conditions PRF95 will be highly unstable even at low pressures.
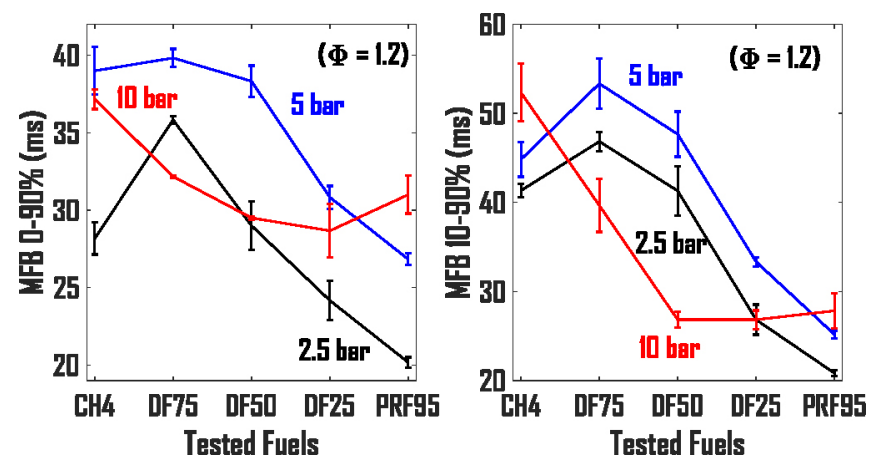

Figure 9. Effects of Pressure on the MFB rates at $\Phi=1.2$

It can be summarized that at each equivalence ratio, the burning rate of all tested fuels showed a similar trend at 2.5 and 5 bar in both flame regimes. At a pressure of 10 bar and especially at rich conditions, all five fuels are likely to have an unstable flame that can mask the effects of pressure on the burning rate. It can be reasonably assumed that the effect of flame instability on the burning rate is stronger than the effect of pressure.

\section{Transition Mechanism - CVCV to Engine}

According to the already described methodology, the MFB rates during stoichiometric engine operation have been calculated from the recorded pressure data illustrated in Figure 10. For the engine experiments natural gas has been used as the gaseous fuel. The experimental study of Baloo et al. [27] reported the laminar flame speed of pure methane and that of natural gas for a range of equivalence ratios at the same initial temperature and pressure. The average difference in the laminar flame speed of natural gas as compared to methane is less than 5\% over the range of the tested equivalence ratios. Also the response of the flame to stretch is found to be very similar for the two gaseous fuels. Therefore for the purpose of the current study it is reasonable to assume that the combustion characteristics of natural gas $\left(92-96 \% \mathrm{CH}_{4}\right.$ mass content) are well approximated by those of pure methane.

The average COV of IMEP among all tested fuels was 2.2\%. At the time of inlet valve closure the difference in pressure between methane having the largest pressure and gasoline having the lowest was less than $7 \%$. As can be observed from Figure 10 the peak pressure corresponds to DF25 and the lowest to methane. The peak pressures of DF50 and DF75 are higher than gasoline. At ignition timing (35 BTDC), methane's pressure is 0.39 bar higher than PRF95. This translated to a calculated $38 \mathrm{~K}$ increase in temperature at ignition for methane. The average temperature (evaluated based on the values of methane and gasoline) was calculated to be $473 \mathrm{~K}$. 


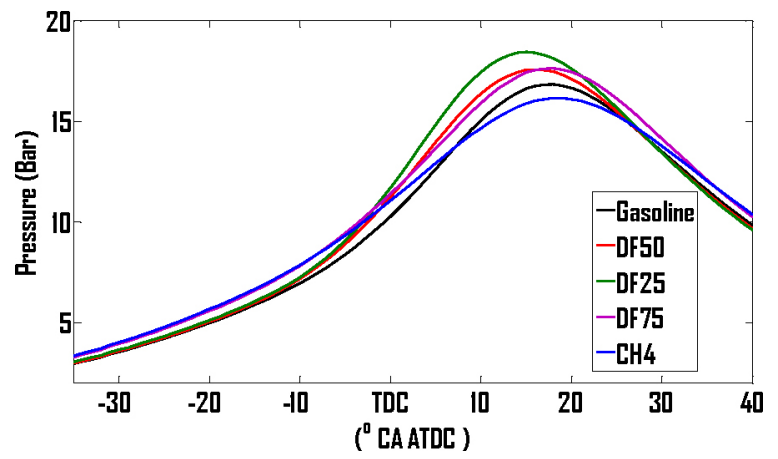

Figure 10. In cylinder pressure during engine experiments at $\Phi=1$

The MFB rates calculated from the engine experiments and presented in Figure 11 showed that the fastest burning rate in both flame regimes corresponds to DF25 followed by DF50. PRF95 and DF75 resulted to have similar burning rates whereas methane is the slowest of all.

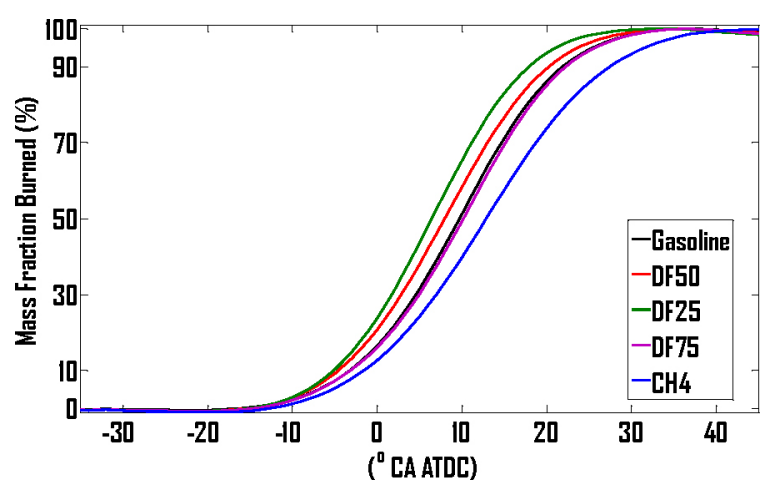

Figure 11. Calculated MFB rates during engine experiments at $\Phi=1$

The MFB durations calculated from the engine experiments as well as the ones at a pressure of 5 bar (absolute) obtained from the constant volume combustion experiments are plotted in Figure 12 in two different axes. A pressure of 5 bar absolute therefore 4 bar gauge was selected as it was the closest to the average pressure (3.1 bar) at ignition timing during the engine experiments.

As can be observed from Figure 12, the burning rate in both flame regimes is increased with a lower DF ratio until a ratio of $25 \%$ is reached (DF25). When there is no addition of gaseous fuel to the liquid fuel, the burning rate is increased again. The trends in the burning rate of the five tested fuels measured inside the engine (dotted lines) are similar to the burning rates measured inside the CVCV. However, the percentage increase of the burning rate with a lower DF ratio is different in the two environments. The burning rate showed different sensitivity among DFs in the engine than in the CVCV experiments.

The MFB duration corresponding to the pure liquid fuel (PRF95 for the CVCV and Gasoline for the engine), has been used as a reference for comparison. The sensitivity of methane and all DFs is defined as the percentage difference from the MFB duration of the liquid fuel. For both experimental environments, the sensitivity with regards to the DF ratio is presented in Figure 13. A DF ratio of $100 \%$ corresponds to $\mathrm{CH}_{4}$ whereas a ratio of $0 \%$ to the pure liquid fuel (reference point).
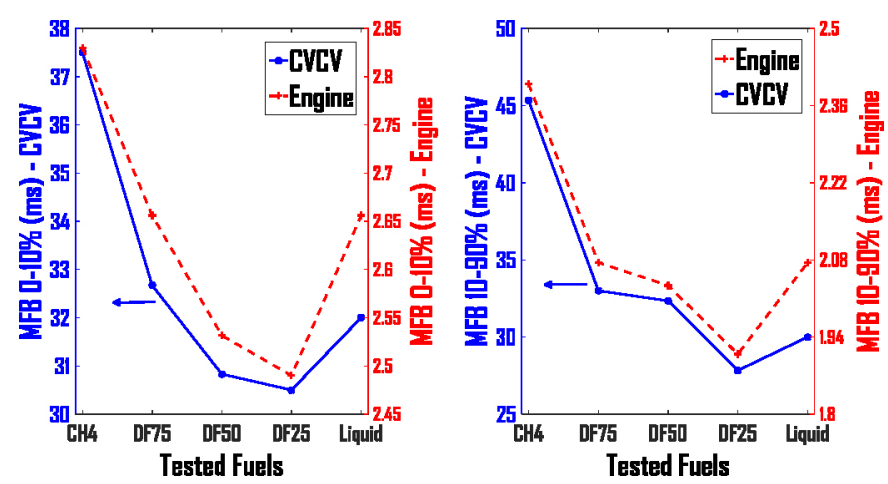

Figure 12. Superimposed MFB rates during CVCV and Engine experiments
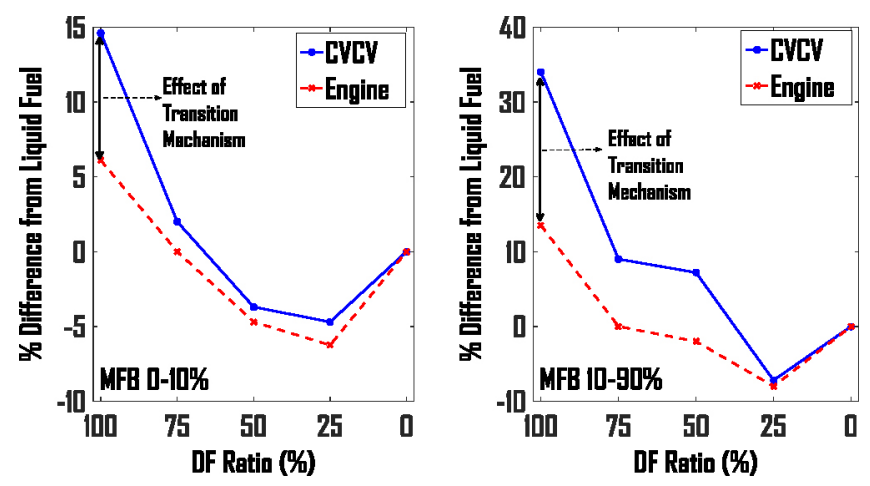

Figure 13. Sensitivity of DF ratio

The sensitivity in the developing and the developed flame regime is decreased with a lower DF ratio in both experimental environments. In the developing flame regime, it can be observed that the sensitivity follows an exponential decrease with the reduction of the DF ratio. Therefore, it can be concluded that in comparison to the liquid fuel the burning rate will not increase further with a DF ratio smaller than about $25 \%$. In the developed flame regime both trends are fairly linear, implying that the mass burning rate will be further increased with a DF ratio smaller than $25 \%$.

The effect of the transition mechanism on the sensitivity of $\mathrm{CH}_{4}$ and all the DFs can be revealed by considering Figure 13. For a particular fuel under consideration, the reduction in sensitivity between the CVCV and the engine experiments is attributed to the transition mechanism. Following the overall trends of Figure 13, it can be observed that the percentage reduction in sensitivity is decreased with a lower DF ratio in both flame regimes. The transition mechanism has its largest effect during $\mathrm{CH}_{4}$ fuelling. As compared to the pure liquid fuel, the transition mechanism will increase the burning rate of $\mathrm{CH}_{4}$ by $8.5 \%$ and $20.5 \%$ in the developing and developed flame regime respectively.

Having evaluated the effects of the transition mechanism on each DF ratio, the contributors to the transition mechanism can now be discussed.

As it is already discussed, the overall effect of the transition mechanism can be revealed by subtracting the MFB durations measured in the engine from the ones measured in the CVCV. It can 
be derived from Figure 12 that during the developing flame regime the effect of the transition mechanism is on average $92 \%$ among the different fuels whereas in the developed regime is $93 \%$. The contributors to the transition mechanism are the effects of piston compression and turbulence. At the point of ignition, the pressure in the CVCV and in the engine environment is within 1 bar whereas the temperature is about $100 \mathrm{~K}$ higher. It is therefore reasonable to assume that during the developing flame regime the effects of pressure on the burning rate between the two experimental environments will be negligible compared to the effects of temperature and turbulence. As reported in literature, at a pressure of 5 bar (absolute), an increase in temperature by $100 \mathrm{~K}$, will increase the laminar flame speed of methane [17] by $39 \%$ and the speed of PRF95 by $25 \%$ [14]. The average laminar flame speed evaluated based on the values of methane and PRF95 will be increased by $32 \%$ attributed to the effects of piston compression. It can be then concluded that the effects of turbulence will increase the burning rate on average by about $60 \%$ among the five tested fuels.

It appears that there is no prior work reporting the laminar flame speed of DF mixtures at elevated pressures and different temperatures. As stated by Baloo et al. [27] and supported by the authors, detailed chemical kinetics of the blend fuel that will develop the understanding on the response of $S_{l}$ with the DF ratio are currently unavailable.

Turbulence was deduced to be the dominant mechanism behind the increase in burning rate from the CVCV as compared to the engine experiments. Turbulence will substantially increase the aerodynamic stretching of the flame between the two experimental environments. It is likely that the reason behind the highest effect of the transition mechanism on $\mathrm{CH}_{4}$ is the lower stretch sensitivity of the methane in comparison to the liquid fuel, evident in the Markstein Length. Methane's Markstein length is the lowest at lean equivalence whereas it's the highest for PRF95 and gasoline. It is then reasonable to expect that at lean conditions the reported differences in burning rate of all DFs in comparison to the pure liquid fuel are expected to increase even further in an engine environment.

It is widely accepted that turbulence is increasing with engine speed [26]. Subsequently for lean mixtures the burning rate of all DFs is also expected to further increase in comparison to the liquid fuel with a higher engine speed.

\section{CONCLUSIONS}

The burning rate of methane-PRF95 Dual Fuels (DFs) was experimentally investigated in a Constant Volume Combustion Vessel (CVCV). Experiments have been conducted at equivalence ratios of $0.8,1,1.2$, pressures of $2.5,5$ and 10 bar and a temperature of $373 \mathrm{~K}$. Methane was added to PRF95 in three different energy ratios $25 \%$, $50 \%$ and $75 \%$. At stoichiometric conditions, experiments have also been performed in an SI research engine. The Mass Fraction Burned (MFB) rates have been used as an indication of the overall burning rate. The MFB rates as well as the transition mechanism between the two experimental environments have been investigated.
Through the current experimental study, it has been found that at 5 bar the fastest burning rate corresponds to PRF95 at rich conditions whereas the slowest to methane at lean conditions. All DFs showed their fastest burning rate at stoichiometric conditions. Interestingly, at lean conditions all DFs were on average $22 \%$ and $27 \%$ faster than PRF95 in the developing (10\% MFB) and the developed (10-90\% MFB) flame regime respectively. At rich conditions PRF95 is the fastest of all whereas DF75 and DF50 are even slower than methane. The burning rate of all fuels showed a similar trend at 2.5 and 5 bar, at all equivalence ratios. At a pressure of 10 bar and especially at rich conditions, all five fuels are likely to have an unstable flame that changed the trend in burning rate compared to the two lower pressures.

An increase in pressure from 2.5 to 5 bar decrease the burning rate of all fuels, at all equivalence ratios. However, the percentage decrease in burning rate at lean conditions is higher than that at stoichiometric conditions, implying a stronger effect of pressure on the burning rate. At a pressure increase from 5 to $10 \mathrm{bar}$, and especially at rich conditions, it is thought that the effect of pressure on the burning rate has been masked by the stronger effect of flame instability

For a particular fuel under consideration, the transition mechanism characterizing the difference in burning rate between the constant volume combustion experiments and those in the engine environment is attributed to the piston compression and the turbulence. The burning rate of all tested fuels has been increased on average by $92 \%$ in the engine as compared to the constant volume combustion experiments. It has been found that turbulence contributed $60 \%$ to the increase in burning rate whereas the piston compression 32\%. The transition mechanism resulted in a larger increase in the burning speed of methane and all DFs in comparison to that of the liquid fuel.

\section{REFERENCES}

1. Tilagone, R., Venturi, S., and Monnier, G., "Natural Gas - an environmentally friendly fuel for urban vehicles: the SMART demonstrator approach," SAE Technical Paper 2005-01-2186, 2005, doi:10.4271/2005-01-2186.

2. Prieur, A. and Tilagone, R., "A Detailed Well to Wheel Analysis of CNG Compared to Diesel Oil and Gasoline for the French and the European Markets," SAE Technical Paper 2007-01-0037, 2007, doi:10.4271/2007$\underline{01-0037}$

3. Semin, R.A., "A Technical Review of Compressed Natural Gas as an Alternative Fuel for Internal Combustion Engines" American J. of Engineering and Applied Sciences 1(4): 302-311, 2008, ISSN: 1941 7020

4. Middleton, A., Neumann, B., and Khatri, D., "Natural Gas Injection System for Buses and Trucks - Potential to Achieve Future Performance and Emission Norms," SAE Technical Paper 2007-26-026, 2007, doi:10.4271/2007-26-026.

5. Delpech, V., Obiols, J., Soleri, D., Mispreuve, L. et al., "Towards an Innovative Combination of Natural Gas and Liquid Fuel Injection in Spark Ignition Engines," SAE Int. J. Fuels Lubr. 3(2):196-209, 2010, doi: $\underline{10.4271 / 2010-01-1513 .}$.

6. Obiols, J., Soleri, D., Dioc, N., and Moreau, M., "Potential of Concomitant Injection of CNG and Gasoline on a 1.6L Gasoline Direct Injection Turbocharged Engine," SAE Technical Paper 2011-01-1995, 2011, doi:10.4271/2011-01-1995.

7. Boretti, A., Lappas, P., Zhang, B., and Mazlan, S., "CNG Fueling Strategies for Commercial Vehicles Engines-A Literature Review," SAE Technical Paper 2013-01-2812, 2013, doi:10.4271/2013-01-2812.

8. Bounaceur, R., Herbinet, O., Fournet, R., Glaude, P. et al., "Modeling the Laminar Flame Speed of Natural Gas and Gasoline Surrogates," SAE Technical Paper 2010-01-0546, 2010, doi:10.4271/2010-01-0546. 
9. Douailler, B., Ravet, F., Delpech, V., Soleri, D. et al., "Direct Injection of CNG on High Compression Ratio Spark Ignition Engine: Numerical and Experimental Investigation," SAE Technical Paper 2011-01-0923, 2011, doi: $10.4271 / 2011-01-0923$.

10. Di Iorio, S., Sementa, P., and Vaglieco, B., "Experimental Investigation of a Methane-Gasoline Dual-Fuel Combustion in a Small Displacement Optical Engine," SAE Technical Paper 2013-24-0046, 2013, doi:10.4271/2013-24-0046.

11. Di Iorio, S., Sementa, P., Vaglieco, B., and Catapano, F., "An experimental investigation on combustion and engine performance and emissions of a methane-gasoline dual-fuel optical engine," SAE Technical Paper 2014-01-1329, 2014, doi:10.4271/2014-01-1329.

12. Tian, G., Daniel, R., Li, H., Xu, H., Shuai, S., Richards, P., Energy Fuels, vol. 24, (2010) pp. 3898-3905, doi:10.1021/ef100452c.

13. Jerzembeck, S., Peters, N., Desjardins, P.P., Peters, H., Combst. Flame vol. 156, (2009), pp. 292-301, doi:10.1016/j.combustflame.2008.11.009

14. Bradley, D., Hicks, R.A., Lawes, M., Sheppard, C.G.W., Wolley, E., Combst Flame, vol. 115 , (1998), pp. 126-144, doi:10.1016/S00102180(97)00349-0.

15. Mannaa, O., Mansour, M.S., Roberts, W.L., Chung, S.H., Combst. Flame, vol. 162, (2015), pp. 2311-2321, doi:10.1016/j. combustflame.2015.01.004.

16. Beeckmann, J., Röhl, O., and Peters, N., "Numerical and Experimental Investigation of Laminar Burning Velocities of iso-Octane, Ethanol and n-Butanol," SAE Technical Paper 2009-01-2784, 2009, doi: $10.4271 / 2009-01-2784$.

17. Gu, X.J., HAQ, M.Z., Lawes, M., Wooley, R., Combst.Flame, vol. 121, (2000), pp. 41-58, doi:10.1016/S0010-2180(99)00142-X.

18. Rozenchan, G., Zhu, D.L., Law, C.K., Tse, S.D., Proc. Combust. Inst., vol. 29, (2002), pp. 1461-1469.

19. Hassan, M.I., Aung, K.T., Faeth, G.M., Combst. Flame, vol. 115, (1998), pp. 539-550, doi:10.1016/S0010-2180(98)00025-X

20. Brequigny, P., Halter, F., Mounaïm-Rousselle, C., Moreau, B. et al., "Thermodiffusive Effect on the Flame Development in Lean Burn Spark Ignition Engine," SAE Technical Paper 2014-01-2630, 2014, doi:10.4271/2014-01-2630.

21. Aleiferis, P., Malcolm, J., Todd, A., Cairns, A. et al., "An Optical Study of Spray Development and Combustion of Ethanol, Iso-Octane and Gasoline Blends in a DISI Engine," SAE Technical Paper 2008-01-0073, 2008, doi:10.4271/2008-01-0073.

22. Zhu, G., Stuecken, T., Schock, H., Yang, X. et al., "Combustion Characteristics of a Single-Cylinder Engine Equipped with Gasoline and Ethanol Dual-Fuel Systems," SAE Technical Paper 2008-01-1767, 2008, doi: $10.4271 / 2008-01-1767$.

23. Aleiferis, P.G., Serras-Pereira, J., Richardson, D., Flame vol. 109 , (2013), pp. 256-278, doi:10.1016/j.fuel.2012.12.088.

24. Pitcher, G., Turner, J., and Pearson, R., "GEM Ternary Blends of Gasoline, Ethanol and Methanol: An Initial Investigation into Fuel Spray and Combustion Characteristics in a Direct-Injected Spark-Ignition Optical Engine Using Mie Imaging," SAE Technical Paper 2012-01$\underline{1740}$, 2012, doi: $10.4271 / 2012-01-1740$.

25. Stansfield, P.A., Ph.D. thesis, Loughborough University, Loughborough, UK, 2009

26. Heywood, J.B., "Internal combustion engine fundamentals", New York: McGraw- Hill Book Co.; 1988

27. Ballo, M., Dariani, B.M., Akhlaghi, M., Chitsaz, I., Fuel, 144 (2015) 264-273

28. Matthews, R. and Chin, Y., "A Fractal-Based SI Engine Model: Comparisons of Predictions with Experimental Data," SAE Technical Paper 910079, 1991, doi:10.4271/910079.

29. Santavicca, D., Liou, D., and North, G., "A Fractal Model of Turbulent Flame Kernel Growth," SAE Technical Paper 900024, 1990, doi: $10.4271 / 900024$

30. Chung, S.H., Law, C.K., Combst.Flame, vol. 72, (1988), pp. 325-336, doi:10.1016/0010-2180/88/503.50.

31. Rakopoulos, C., Michos, C., and Giakoumis, E., "Thermodynamic Analysis of SI Engine Operation on Variable Composition BiogasHydrogen Blends Using a Quasi-Dimensional, Multi-Zone Combustion Model," SAE Int. J. Engines 2(1):880-910, 2009, doi:10.4271/2009-01$\underline{0931}$.

\section{CONTACT INFORMATION}

Professor Rui Chen

Department of Aeronautical \& Automotive Engineering Loughborough University, LE11 3TU, United Kingdom r.chen@1boro.ac.uk

Phone: +44(0)1509 227255

\section{Sotiris Petrakides}

Department of Aeronautical \& Automotive Engineering Loughborough University, LE11 3TU, United Kingdom S.Petrakides@lboro.ac.uk

Phone: +44(0)1509 227245

\section{Professor Haiqiao Wei}

State Key Laboratory of Engines (SKLE), Tianjin University, Tianjin, China

whq@tju.edu.cn

Phone: +86(0) 22-27891285

\section{ABBREVIATIONS/NOMENCLATURE}

$\boldsymbol{\rho}_{\mathbf{u}}$ - Unburned gas density

$\mathbf{A}_{\mathbf{f}}$ - Actual flame surface area

$\mathbf{A}_{1}$ - Laminar flame surface area

$\mathbf{A}_{\mathbf{f}}^{\prime}$ - Actual flame surface area in $\mathrm{CVCV}$

$\mathbf{S}_{1}$ - Laminar flame speed

I $_{\mathbf{0}}$ - Flame stretch factor

$\mathbf{c}_{\mathrm{i}}$ - Mixture's composition

$\mathbf{u}_{\mathbf{t}}$ - Turbulence characteristics

$\mathbf{I}_{\mathbf{0}}$ - Flame stretch factor in $\mathrm{CVCV}$

P - Pressure

$\mathbf{T}_{\mathbf{u}}$ - Unburned gas temperature

$\boldsymbol{\Phi}$ - Equivalence ratio

$\mathbf{M}_{\mathbf{C H}_{4}}$ - Mass of methane

$\mathbf{M}_{\text {PRF95 }}$ - Mass of PRF95

LHV - Latent Heat of Vaporization

TDC - Top Dead Centre

BDC - Bottom Dead Centre

BTDC - Before Top Dead Centre

ATDC - After Top Dead Centre

ABDC - After Bottom Dead Centre

AFR - Air to Fuel Ratio

MAF - Mass Air Flow

IMEP - Indicated Mean Effective Pressure

NEDC - New European Driving Cycle

COV - Coefficient Of Variation

CVCV - Constant Volume Combustion Vessel

MFB - Mass Fraction Burned

HRR - Heat Release Rate 


\section{APPENDICES}

\section{APPENDIX A1}

For a homogeneous SI engine combustion process the burning rate is given by,

$$
\dot{m}_{b, \text { engine }}=\rho_{u} S_{L} A_{f} I_{0}=\rho_{u} S_{L} A_{l} I_{0} \frac{A_{f}}{A_{l}}
$$

The unburned gas density $\left(\rho_{u}\right)$ can be defined as,

$$
\rho_{u}=\frac{P}{\frac{R T_{u}}{W_{u}}}
$$

where $R$ is the gas constant, and $W_{u}$ is the molecular weight of the unburned mixture. Therefore,

$$
\rho_{u}=f\left(P, T_{u}, \Phi, c_{i}\right)
$$

$S_{l}$ is a function of the thermochemical properties of a combustible mixture,

$$
S_{l}=f\left(P, T_{u}, \Phi, c_{i}\right)
$$

$A_{l}$ is the surface area the flame would have if it was propagating with its laminar speed. It is also depended on the thermochemical properties of the combustible mixture,

$$
A_{l}=f\left(S_{l}\right)
$$

Consequently,

$$
A_{l}=f\left(P, T_{u}, \Phi, c_{i}\right)
$$

In an engine environment $A_{f}$ will be also affected by the turbulence characteristics,

$$
\mathrm{A}_{\mathrm{f}}=f\left(P, T_{u}, \Phi, c_{i}, u_{t}\right)
$$

Using Fractal Geometry [28] the ratio of turbulent to laminar flame surface area $\left(\frac{A_{f}}{A_{l}}\right)$ can be modelled as,

$$
\dot{m}_{b, \text { engine }}=\rho_{u} A_{l} S_{L} I_{0}\left(\frac{L_{M a x}}{L_{\text {Minl }}}\right)^{D-2}
$$

Where $\left(\frac{L_{\text {Max }}}{L_{\text {Min }}}\right)$ is the ratio of the flame wrinkling scales, and $D$ is the fractal dimension.

The ratio of the flame wrinkling scales can be well approximated by the ratio of integral length scale $\left(I_{i}\right)$ to the Kolmogorov scale $(\eta)[\underline{28}]$ as,

$$
\frac{L_{\text {Max }}}{L_{\operatorname{Min}}} \approx \frac{I_{i}}{\eta}
$$

The ratio of the flame wrinkling scales will be affected by the turbulence levels inside the engine. Therefore, 


$$
\frac{L_{\operatorname{Max}}}{L_{\operatorname{Min}}}=f\left(u_{t}\right)
$$

According to Liou et al. [29] the fractal dimension $(D)$ which characterizes the roughness or degree of wrinkling of the flame surface is defined as,

$$
D=2.35 \frac{u^{\prime}}{u^{\prime}+S_{l}}+2 \frac{S_{l}}{u^{\prime}+S_{l}}
$$

Thus,

$$
D=f\left(P, T_{u}, \Phi, c_{i}, u_{t}\right)
$$

Considering negligible heat loss from the flame, Lewis and Prandtl numbers of approximately one and a small effect of the stretch on the flame speed, the flame stretch factor can be modelled as $[\underline{30}]$,

$$
I_{o}=1-\frac{v}{S_{l}^{2}} K
$$

The flame stretch rate $(K)$ is constituted from the additive contributions of the geometric $\left(K_{g}\right)$ and turbulent $\left(K_{t}\right)$ stretch rates $[\underline{31}]$ as,

$$
K=K_{g}+K_{t}=\frac{1}{A_{f}} \frac{d A_{f}}{d_{t}}+\frac{u^{\prime}}{\lambda}
$$

Assuming a spherical expanding flame with its laminar flame thickness $\left(\delta_{l}\right)$ very small compared to its flame $\operatorname{radius}\left(r_{f}\right)$,

$$
K=\frac{2}{r_{f}} \frac{\rho_{u}}{\rho_{b}} S_{l}+\frac{u^{\prime}}{\lambda}
$$

Thus $I_{o}$ is dependent on,

$$
I_{o}=f\left(P, T_{u}, \Phi, c_{i}, u_{t}\right)
$$

Therefore the mass burning rate inside an engine is highly not linearly depended on the following parameters,

$$
\dot{m}_{b, \text { engine }}=f\left(P, T_{u}, \Phi, c_{i}, u_{t}\right)
$$

\section{APPENDIX A2}

The mass burning rate in a CVCV is given by:

$$
\dot{m}_{b, c v c v}=\rho_{u} A_{f}^{\prime} S_{L} I_{0}^{\prime}
$$

With the nonexistence of turbulence in the $\mathrm{CVCV}$, there is only a contribution from the geometric flame stretch rate on the flame stretch factor. Hence the flame stretch factor is given by,

$$
I_{0}^{\prime}=1-\frac{v}{S_{l}} \frac{2}{r_{f}} \frac{\rho_{u}}{\rho_{b}}
$$


Thus inside the CVCV, $I_{0}^{\prime}$ is depended only on,

$$
I_{0}^{\prime}=f\left(P, T_{u}, \Phi, c_{i}\right)
$$

With the nonexistence of turbulence, the flame surface area is affected by the stretched burning speed $\left(S_{L} I_{0}^{\prime}\right)$ and by the phenomena of flame instability. In a CVCV both stretched burning speed and flame instability are thermochemical parameters of the combustible mixture, thus $A_{f}^{\prime}$ is depended on,

$$
A_{f}^{\prime}=f\left(P, T_{u}, \Phi, c_{i}\right)
$$

Following the previous analysis, it can be concluded that the mass burning rate during the experiments in the CVCV is depended only on the thermochemical parameters of the combustible mixture.

$$
\dot{m}_{b, c v c v}=f\left(P, T_{u}, \Phi, c_{i}\right)
$$

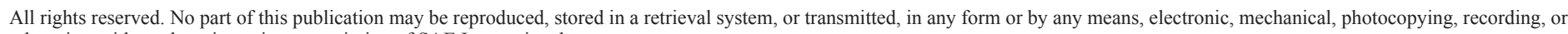
otherwise, without the prior written permission of SAE International.

Positions and opinions advanced in this paper are those of the author(s) and not necessarily those of SAE International. The author is solely responsible for the content of the paper. 